\title{
Memoria de Don José Miguel de Barandiarán
}

\author{
ana María muñoz amilibia
}

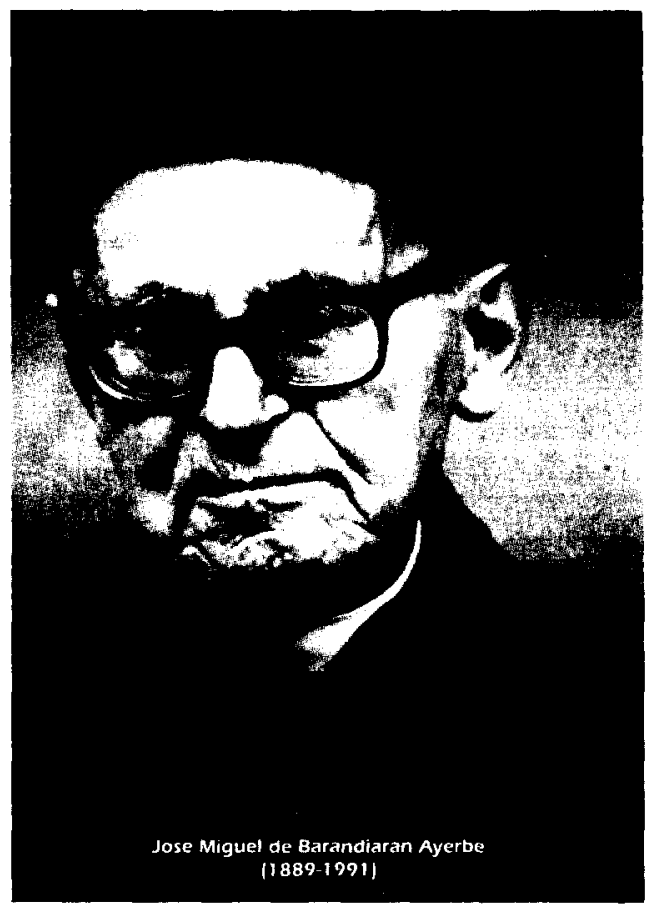

El 21 de diciembre de 1991, falleció en Ataún Don José Miguel de Barandiarán. Había nacido en el mismo pueblo guipuzcoano el 31 de diciembre de 1889. Por tanto, le faltaban sólo diez días para cumplir los 102 años de vida, - ya los había cumplido si - cómo a el mismo le gustaba comentar - se tenía en cuenta los nueve meses anteriores desde su concepción.

Su larga vida, su incansable dedicación a la investigación antropológica, particularmente del pueblo vasco, le merecieron numerosos reconocimientos, sobre todo en los últimos años de su vida: La Gran Cruz de Carlos III cuando ya había cumplido cien años, el calificativo de "Patriarca de la cultura vasca», que le otorgaba con cariño su pueblo o la edición de sus Obras Completas, que, sin embargo, no hubiera sido posible sin su laboriosidad y dedicación personal, unidas a un riguroso orden y método, característicos de su personalidad desde los años juveniles.

Aunque es mucho lo que se ha escrito sobre Don José Miguel con motivo de su fallecimiento, he querido ahora recordarlo en nuestra revista 
de la UNED, más que para destacar la importancia y el interés de sus trabajos científicos, para intentar dar unas pinceladas sobre su extraordinario perfil humano. Me mueve a ello, el haber tenido la suerte de conocerle cuando, con otros estudiantes, colaboraba en sus excavaciones arqueológicas del verano guipuzcoano, y mi agradecido reconocimiento a su magisterio en mi formación arqueológica y humana.

Acababa de regresar de su exilio francés, cuando emprendió las excavaciones de Letzetxiki. No sólo nos enseñó la cuidadosa técnica del decapage y el riguroso registro tridimensional de todas las piezas, que iba dibujando cuidadosamente, sino que además, nos enseñaba a amar la ciencia y a ser personas pacientes y comprensivas.

Pertenecía a una raza de sacerdotes sabios y sencillos, que no me atrevo a decir que se ha extinguido, pero que desde luego, si persiste, ha debido de cambiar mucho, como los tiempos. Era ante todo cura, como lo fue el que aquí llamamos Abate Breuil. Un curita menudo y enérgico, austero y laborioso, extremadamente sociable, abierto, sincero, que se manifestaba siempre con toda naturalidad. Ante un gran personaje o ante un simple estudiante, porque ante todo amaba al ser humano, le interesaba y lo respetaba, ya que toda su vida la dedicó precisamente a conocerlo y estudiarlo, a plantearse las cuestiones más sencillas o más transcendentes en torno a él. Por eso le interesaron la Prehistoria, la Filosofía, la Teología o la Historia de las Religiones y sobre todo la Antropología y Etnografía, como suma de todos los aspectos del conocimiento del ser humano y de su capacidad de creación.

Era además un gran conversador, ameno y con gran sentido del humor; un humor a veces socarrón como buen vascongado, pero siempre respetuoso y sin herir a los demás. Los que entonces éramos jóvenes nos lo pasábamos en grande oyéndole hablar y aprendíamos mucho en aquella Escuela de la vida. Preferíamos pasar quince o veinte días excavando con él que disfrutando de las playas cantábricas. Nunca se quitaba su alzacuellos de sacerdote, ni siquiera debajo del mono que utilizaba para excavar. Aunque su salud siempre había sido delicada y su cuerpo frágil, nunca desfallecía, ni monte arriba, ni lloviendo, ni soportando el calor, siempre guardando un régimen alimenticio, suficiente para mantenerse en forma, como largamente demostró. Mi afecto y admiración hacia Don José Miguel hicieron que, después de aquellos años felices y fructíferos, procurara visitarle en su retiro de Villa Sara de Ataun cuando en verano volvía a San Sebastián. Me preocupaba distraerle, interrumpir su trabajo, pero como siempre nos recibía con tanto cariño y hospitalidad, charlando de los temas más diversos, al año siguiente se repetía la visita. 
Fue además un gran pensador y nunca le abandonó el afán por conocer la verdad a través de la ciencia y la religión. Muy expresiva de esta realidad es su frase tantas veces recogida: "Gracias a que fui cura fui científico». O su creencia en que "La verdad profesada por la religión, es la que con medios humanos investiga la ciencia: ambas hacen el saber humano". Siempre defendió que la ciencia fuera ante todo empírica, mas que teórica, sólo se podía investigar la realidad conocida. Para él, el agnosticismo sería la confesión de la propia ineptitud, la actitud menos fecunda y más inútil en el campo de la investigación, de la ciencia y de la propia vida.

Este sentido empírico de la ciencia, la convicción de que era necesario conocer lo mejor posible la realidad, para tener una base firme como punto de partida, explica la intensidad y profundidad de su trabajo de campo, tanto en Prehistoria como en Etnografía. Eso explica también su dedicación a estudiar y conocer lo más próximo, el País Vasco, aunque no por ello su trabajo adoleciera de provincianismo. Su espirutu inquieto y curioso le llevaba a "estar al día» de lo que acontecía en todas partes y de las novedades del mundo científico. Pero era consciente de la fragilidad del patrimonio etnográfico y de la rapidez con que se transformaban o desaparecian muchas manifestaciones culturales. Por ello, durante su larga vida, se esforzó en recoger testimonios directos, personalmente, y encauzando una metodología de encuestas mediante unas fichas modélicas, que fueron de gran utilidad. El material recogido es ingente y además lo fue dando a conocer a través de numerosas revistas, y muy particularmente en el Anuario de Eusko Folklore. Por suerte, ahora sus trabajos son mas accesibles, recopilados en sus Obras Completas.

En Prehistoria fue pionero desde 1916 junto con Aranzadi y Eguren - los "Tres tristes trogloditas"-, según nos recordaba festivamente que les habían calificado, excavando y prospectando por todo el País Vasco. Una buena síntesis de estos trabajos nos la dio Don José Miguel en su obra El hombre prehistórico en el pais vasco, Buenos Aires 1953. Este librito, pequeño por su tamaño, pero grande por su contenido y con ilustraciones hechas por el propio autor, nos muestra el nivel alcanzado por sus estudios de Prehistoria hace cuarenta años. En la introducción ya se perfilan cuales eran sus objetivos: "Las investigaciones arqueológicas y etnográficas efectuadas en el territorio vasco, principalmente durante la primera mitad de este siglo, nos han dado a conocer la existencia de una población pirenaica anterior a la historia y nos han permitido columbrar su proceso multisecular y la evolución de sus modos de vida y de sus concepciones míticas y religiosas". $Y$ algo que convendría recordar ahora que - «en busca de su identidad" - proliferan tanto los estudios mas o menos locales: "Atendiendo tan sólo a los materiales recogidos en los 
Pirineos occidentales, no seria posible conocer la prehistoria vasca. Muchos de los hechos que registra la arqueología pirenaica cubren extensas áreas de las regiones periféricas, 10 que demuestra que la población de los valles vascos no estuvo aislada en ninguna época. Por eso su estudio resultaria acéfalo si lo desconectáramos del cuadro general de la prehistoria del SW de Europa".

El libro es de un orden y corrección extremados, exponiendo toda la documentación arqueológica, incidiendo en los hallazgos de fauna, sus porcentajes..., buscando siempre la interpretación de los datos y sobre todo de la vida del hombre prehistórico en las distintas épocas, utilizando para ello ejemplos de la etnografía vasca que tan bien conocía. Así, como ejemplo de caza con trampas y fosas, combinado con el ojeo, se refiere a la practicada en el País Vasco para capturar lobos, vacas y caballos monteses, ilustrándola con dibujos de una lobera u otsaleku, de la makilla, porra arrojadiza usada por los pastores, o los lazos corredizos (bizto o lakio,) que incluso parece adivinar en un caballo grabado en la cueva de Urtiaga. O la caza de aves con red, tan bien ilustrada en las palomeras de Echalar.

Pero es sobre todo interesante su interpretación del arte rupestre desde el Auriñaciense de Isturitz. "No sólo proporciona el conocimiento de la fauna de su época, sino también el objeto $y$, a veces, la técnica de las prácticas cinegéticas, $y$, además algunos rasgos de su mundo conceptual y las preocupaciones fundamentales de la vida humana". Algunas figuras de animales heridos con flechas o cogidos en trampas o lazos recordarían procedimientos mágicos, para buscar la multiplicación de las especies representadas y asegurar su captura. Algunos fenómenos de magia de la población rural vasca podrían acercarnos a la comprensión de esta mentalidad. "Tales son: actuar sobre las imágenes y los símbolos de las cosas para producir en éstas los efectos deseados; efectuar gestos mímicos para provocar el fenómeno o la acción que se imita; poseer ciertos objetos para ejercer influencia sobre otros de su género. En la base de esta conducta se descubre la creencia de que la imagen y el símbolo se hallan en conexión ineluctable con los objetos representados...». Esta concepción mágica sería una de las bases de la civilización paleolítica. Otras producciones del arte paleolítico podrían responder en cambio, a una concepción religiosa: las figuras de animales sin cabeza y la mayor parte de las que no ostentan atributos de caza. Su forma, su ubicación, concuerdan con las figuras de caballos, toros, cabras, carneros, buitres y serpientes, que, según la mitología pirenaica, adoptan los genios o divinidades que moran en el interior de las cavernas. Figura destacada entre ellas es la de Mari, genio o divinidad antropomorfa femenina troglodita que a veces adopta la forma de animal. Además, "La religión y la magia 
ligan a los hombres entre sí y con las cosas, creando relaciones juridicas (derechos, interdicciones y sanciones) con repercusiones en el derecho individual (o interindividual) y social y en la justicia conmutativa y distributiva».

Esto son sólo algunos ejemplos de la interpretación etnoarqueológica de Don José Miguel de Barandiarán, con la ventaja de que, en su caso, la distancia estaba al menos sólo en el tiempo no en el espacio, lo que le hacía pensar que «Los mitos pirenaicos que han llegado hasta nuestros días en la tradición del pueblo vasco, proyectan sombras y figuras gemelas de las del cazador paleolítico o, lo que es más probable, heredadas de ellas". No era mi intención extenderme en aspectos concretos de su contribución científica, sino mas bien intentar poner algún ejemplo de la coherencia de sus trabajos siempre en torno a la mejor comprensión del hombre y su destino, a través precisamente de sus manifestaciones religiosas y culturales.

Destaca en su pensamiento el concepto de humanismo, guizabidea en vascuence. Término difícil de traducir o asimilar al concepto que normalmente se tiene del Humanismo en la cultura occidental: El hombre, como único ser inteligente, es también el único que se plantea los grandes interrogantes sobre el sentido de la vida y del mundo que le rodea y, en función de ello se desarrolla la cultura humana, con distintas manifestaciones en las diversas áreas. La cultura vasca presenta todos los componentes de una forma propia de ser hombre. En ella es fundamental el hecho de la contingencia humana y el reconocimiento de un ser (Jainko) que trasciende al hombre y al mundo como principio y referencia final. La aceptación del cristianismo reforzó y concretó estos principios reconocidos tradicionalmente, manifestándose en las creencias y formas culturales: Supervivencia de la persona humana; la familia troncal formada por miembros ahora presentes y antepasados difuntos; paridad del hombre y la mujer en la representación de la casa y en la sucesión hereditaria; derecho de la casa a su integridad y a su inviolabilidad como lugar sagrado respetado hasta por los genios; vecindad y pueblo, complementos de la casa; lengua euskera que revela una imagen singular del mundo y conserva vestigios de cultura antiquísima. El humanismo tradicional en el País Vasco se basaba en el amor a Dios y al prójimo, base también de la justicia, el derecho, el deber y la responsabilidad, seguramente por influencia cristiana.

En los últimos años de su vida contemplaba la pérdida de los valores tradicionales, sobre todo el papel de la familia en la educación de los hijos: "Antes, la primera cultura se tenía en la familia y era una cultura tradicional cristiana. Hoy no hay tiempo para eso, apenas se recibe nada 
a través de los padres, éstos tienen otro modo de ver las cosas, no se si es una nueva civilización». Le preocupaba la violencia, en un pueblo como el vasco, tradicionalmente pacífico y su mayor deseo era la paz.

Su concepto de humanismo, como conducta humana (Gizabidea), quedó resumido en 1989 en un breve texto que la Fundación José Miguel de Barandiarán reproduce en el recordatorio de su fallecimiento, y cuya difícil traducción tengo que agradecer a mi buena amiga Esperanza Garmendia Elósegui:

\section{HUMANITARISMO (Conducta humana)}

"Al ser humano frecuentemente le surgen preguntas como estas: ¿Qué soy yo? Yo, ¿para qué soy?

Las respuestas que les damos a estas preguntas nos expresan el Humanitarismo.

¿Qué soy yo? Un ser humano que tiene inteligencia, y por medio de ésta, la que conduce y hace andar en muchos casos a su conducta.

Sin embargo en mi ínterin no estoy para cualquier cosa. Si estuviera interinamente para todas las cosas, no me moriria por lo menos. Pero...

Yo, ¿para qué soy? No siendo en mi interior, tendría que ser en el interior de otro. Ese otro uno es anterior a mí y más grande sin duda; es decir Dios. Tengo que confesar eso y amarle a Él. He ahí pues un quehacer mío. Por consiguiente soy para eso; para amar a Dios y a nuestros prójimos que Él ama.

He ahí el humanitarismo o su fundamento.

En Ataún a 20 de noviembre de 1989».

Firmado: José Miguel de Barandirarán

Resumen biográfico proporcionado por la Fundación José Miguel de Barandiarán.

Don José Miguel de Barandiarán Ayerbe, nació el 31 de diciembre de 1889 en Ataún (Guipúzcoa).

- Cursó estudios de Humanidades en la preceptoría de Baliarrain (Guipúzcoa) y de Filosofía y Teología en el Seminario Conciliar de Vitoria.

- En el verano de 1913 acudió a los cursos que el profesor Wundt, autor de la monumental obra Völkerpsychologie, impartió en la Uni- 
versidad de Leipzig. Las orientaciones que recibió de dicho profesor marcaron el rumbo de sus posteriores investigaciones antropológicas y etnográficas.

- Ordenado sacerdote en diciembre de 1914, obtiene la Licenciatura en Teología en la Universidad Eclesiástica de Burgos en 1915.

- En 1916 publicó en la revista Euskalerriaren Alde, editada en San Sebastián, su primer trabajo titulado "Ataún en la Edad Media".

- Profesor del Seminario de Vitoria, pronuncia el discurso inaugural del curso 1917-18 sobre «Prehistoria Vasca». A raíz de la publicación de este discurso, entabló relación con el eminente prehistoriador francés Henri Breuil, quien le puso en contacto con el prehistoriador alemán Obermaier.

- El mismo año 1917, había establecido su primer contacto con el que sería su maestro, el Dr. Aranzadi, a la sazón catedrático de la Universidad de Barcelona. Junto con el Dr. Eguren, catedrático de Oviedo, forman el equipo de arqueólogos que trabajaron conjuntamente durante 20 años, hasta 1936.

- En 1992 y en compañia del profesor Aranzadi, realiza una gira por Europa visitando Museos e Instituciones en París, Colonia, Maguncia, Munich, Leipzig, Berlín, Holanda, Akisgrán, Tilburg.

En esta última ciudad holandesa presenta en septiembre, la ponencia "La religión des anciens Basques» en el Congreso Internacional de Etnología religiosa.

- En 1926 es nombrado Rector del Seminario de Aguirre y Vice-rector del Seminario Conciliar. Según su amigo y co-profesor Don Manuel de Lekuona, Barandiarán «fue el gran propulsor de una reforma radical, en sentido científico de los estudios en el Seminario de Vitoria y en un modo más amplio en los Estudios Vascos», impulsando las ciencias naturales y antropológicas.

- En 1929 emprende un segundo viaje de estudios de nuevo con el Dr. Aranzadi, recorriendo las sociedades e institutos antropológicos en Barcelona, Lyon, Ginebra, Berna, Zurich, Viena, Innsbruck, Luzerna, Interlaken y Burdeos.

- En el periodo comprendido entre 1917-1936, en compañía de los doctores Aranzadi y Eguren, lleva a cabo un plan sistemático de excavaciones arqueológicas sobre todo el territorio del País Vasco: Dólmenes de la sierra de Aralar (1917), de la sierra de Aizgorri (1918), de Ataún-Burunda (1919), de Altzania (1920), de la sierra de Encia y de Elosua Placencia (1921), de Belabieta y Urbasay Grutas 
Artificiales de Álava (1922). De nuevo Aralar (1923), Caverna de Santimamiñe (1924, 1925 y 1931), Lumentxa en 1925. Cavernas de Ermittia y otras de Guipúzcoa (1924 y 1927), Bolinkoba (1933), UrtiagaItziar (1936).

- En 1931 publica la obra Breve historia del Hombre Primitivo dentro de los trabajos que venía publicando en el Anuario Eusko Folklore.

- En 1934 publica en doble versión euskérica y castellana su obra de síntesis: El Hombre Primitivo del País Vasco.

- En 1935 en la reunión de Londres, es nombrando miembro del Consejo Permanente del Congreso Internacional de Antropología y Etnografía.

- En 1939 participa en el Congreso Internacional de Antropología en Copenhague con la ponencia «Sobre las antiguas Religiones de los Vascos".

- A raíz de la guerra civil, desde 1936 a 1953, reside en el Departamento de los Bajos Pirineos y desde 1942 en el pueblo de Sara.

- En 1946 crea el Institut Basque de Recherches, denominado IKUSKA y comienza a editar un boletín del mismo nombre con las investigaciones realizadas.

- En 1947 es nombrado Director de la Sociedad Internacional de Estudios Vascos que aglutina en su publicación EUSKO JAKINTZA a los estudios europeos más renombrados en la vascología.

- Durante el período 1946-1950 participa intensamente en congresos internacionales: Londres y Oxford (1946), París, Congreso de Archeocivilizacion (julio 1947), Musée de l'Homme (septiembre 1947), París (1948), Bruselas (1948), Bruselas (1949).

- En 1953 retorna al País Vasco y pronuncia en la Universidad de Salamanca, a requerimiento de su Rector el prof. Tovar, su conferencia sobre El estado actual de los Estudios vascos.

- En 1956 comienza a reeditar, a partir del volumen XV, el Anuario de Eusko Folklore, bajo el patrocinio de la Sociedad de Ciencias Aranzadi y reemprende sus investigaciones arqueológicas creando nuevos equipos de jóvenes investigadores. Exploraciones en los yacimientos de Leizetxiki, Aitzbitarte, Kurtzia, Atxeta, Urtiaga, Axlor, Ekain, entre otros.

- Desde 1965 a 1977 regenta la cátedra de Etnología vasca creada en la Universidad de Navarra. Establece el plan Etniker, formando en todas las regiones vascas equipos de investigadores y colabo- 
radores que lleven adelante un plan sistemático de recogida etnográfica con objeto de elaborar el Atlas Etnográfico de Euskalerria.

- En 1972 la Gran Enciclopedia Vasca de Bilbao comienza a editar sus Obras Completas que contemplarán un total de 22 volúmenes.

- En 1973 crea el grupo de investigación etnográfica Etniker-Bizkaia, cuya sede social es Euskal Biblioteca Labayru de Derio.

- En 1976 en unión de D. Manuel Lekuona, dres. Irigaray y Gárate, D. Manuel de Irujo y D. Agustín Zumalabe, componentes de la última Junta Permanente de la Sociedad de Estudios Vascos, pone de nuevo en marcha esta Sociedad. En la Asamblea General de Onate, de septiembre del mismo año, es nombrado por unanimidad Presidente de Eusko Ikaskuntza.

- En abril de 1978, la Universidad del País Vasco le otorga el Doctorado Honoris Causa. Igual galardón le otorga en 1981 la Facultad de Teología de Vitoria.

- En 1983, la Diputación Foral de Guipúzcoa le nombra Hijo Predilecto de la Provincia.

- En octubre de 1986, la Universidad de Deusto le otorga el Doctorado Honoris Causa.

- El 28 de enero de 1987, en un solemne acto, celebrado en el Paraninfo de la Universidad Complutense de Madrid y en presencia de todo el Claustro, recibe el Doctorado Honoris Causa.

- En diciembre de 1987 Eusko Jaurlaritza le otorga la Cruz del Arbol de Guernika.

- El 20 de abril de 1988, Eusko Ikaskuntza y D. José Miguel de Barnadiarán crean la Fundación Barandiarán.

- En 1990 la Diputación foral de Bizkaia le nombra "Seme Bikaina", y también se le concede la Medalla de Oro al Mérito en las Bellas Artes, la Medalla de Oro del Gobierno de Navarra, la Gran Cruz de Carlos III, la insignia de Oro y Brillantes del Ayuntamiento de San Sebastián y la Medalla de Oro de la Diputación Foral de Álava.

- El 21 de diciembre de 1991, Festividad de Santo Tomás, fallece en Ataún a las cinco de la madrugada. 